DOCUMENTS

pour l'histoire

des techniques
Documents pour l'histoire des techniques

Nouvelle série

$14 \mid 2^{\mathrm{e}}$ semestre 2007

Actes de la journée d'études doctorales en histoire des techniques (8 mars 2004)

\title{
Cyrille Simonnet, Le Béton, histoire d'un matériau. Économie, technique, architecture
}

Paris, éd. Parenthèses, 2005. 220 pages. Ill., index des noms propres, bibliographie et biographie.

\section{André Guillerme}

\section{QpenEdition}

Édition électronique

URL : http://journals.openedition.org/dht/1135

DOI : 10.4000/dht. 1135

ISSN : 1775-4194

Éditeur :

Centre d'histoire des techniques et de l'environnement du Cnam (CDHTE-Cnam), Société des élèves du CDHTE-Cnam

\section{Édition imprimée}

Date de publication : 1 décembre 2007

Pagination : 155-157

ISBN : 978-2-9530779-0-2

ISSN : 0417-8726

Référence électronique

André Guillerme, «Cyrille Simonnet, Le Béton, histoire d'un matériau. Économie, technique, architecture », Documents pour I'histoire des techniques [En ligne], 14 | $2^{\mathrm{e}}$ semestre 2007, mis en ligne le 03 novembre 2010, consulté le 24 septembre 2020. URL : http://journals.openedition.org/dht/1135 ; DOI : https:// doi.org/10.4000/dht. 1135

Ce document a été généré automatiquement le 24 septembre 2020.

(c) Tous droits réservés 


\section{Cyrille Simonnet, Le Béton, histoire d'un matériau. Économie, technique, architecture}

Paris, éd. Parenthèses, 2005. 220 pages. Ill., index des noms propres, bibliographie et biographie.

\section{André Guillerme}

\section{RÉFÉRENCE}

Cyrille Simonnet, Le Béton, histoire d'un matériau. Économie, technique, architecture, Paris, éd. Parenthèses, 2005. 220 pages. Ill., index des noms propres, bibliographie et biographie.

1 Voici un travail accompli, une somme définitive. L'ouvrage présenté par Cyrille Simonnet est armé d'une thèse soutenue en 1998, distillée, enluminée notamment d'une trentaine de très belles illustrations pleine page, et mise en œuvre avec beaucoup d'intelligence. La bibliographie, internationale, classée, cumule près de quatre cents ouvrages de toutes disciplines, quasiment exhaustive - il y manque la littérature russe, abondante mais difficilement accessible. Neuf biographies, neuf portraits - Vicat, Coignet, Hennebique, Rabut, Freyssinet, Maillart, Duiker, Nervi, Perret - résument l'aventure d'un matériau composite, délicat, fondateur et qui s'élève, grandit, presque volatile. Neuf hérauts d'une épopée technique et architecturale, porteurs d'autant de chapitres équilibrés, bien assis, agréablement écrits, trop français sûrement.

On aurait aimé une introduction, académique pourquoi pas, faisant l'état de la recherche, des sources écrites, orales et iconographiques, ébauchant une problématique, esquissant une méthode de pensée, retendant les liens avec l'économie, la technique et l'architecture. Il manque aussi une conclusion - l'épilogue (pp. 189191) n'est qu'un résumé - sur ce patrimoine finalement " industriel », sa monumentalité. Il est vrai que cette œuvre n'est plus une thèse mais une synthèse. 
3 «L'âme de la maçonnerie » et «les sciences du ciment », les deux premiers chapitres, commentent l'histoire maintenant bien connue du matériau composite, ou mieux sa proto-histoire. Les recherches savantes des académiciens de la fin du XVIIe et du XVIIIe siècles - Perrault, Macquer, Guyton de Morveau - n'arrivent pas à résoudre le problème de la non-dureté des mortiers contemporains face aux témoins du mortier romain. Ils butent sur l'hétérogénéité de la composition, sur les a priori chimiques ou mécaniques. Cyrille Simonnet souligne bien cette volonté de retrouver la compacité romaine, la dureté qui assure la pérennité du monument. Chaux + silice ou mieux sa forme saline, le silicate de chaux: la formule grossière est ébauchée par Faujas de Saint-Font (1778), retrouvée et affinée par Vicat (1816). Il aurait été bon d'y ajouter le Berlinois John (1815), mais aussi le céramiste Brongniard (1772), le chimiste Macquer et surtout le pharmacien Baumé comme Vicat ou Smeaton. La diffusion du savoir est encore très cloisonnée: ni Baumé, ni Macquer ne parlent de mortier, ni Smeaton ni Guyton de céramique.

4 La chaux hydraulique est découverte vers 1815 à force d'expériences et à force d'en parler aux artistes, architectes et ingénieurs civils et militaires - dont il est malheureusement peu parlé et qui ont été déterminants, comme le colonel Treussart, directeur des fortifications de Strasbourg, qui torréfie des argiles et «invente » les pouzzolanes artificielles. Les architectes sont présents - Lafaye, Loriot, Fleuret, Rondelet. Lebrun, architecte départemental du Tarn-et-Garonne aurait mérité plus de considération et de figurer parmi les hérauts du béton : il a conçu et réalisé la première maison tout en béton près de Gaillac, magnifique demeure en voie de classement comme monument historique...

5 «Inventions du béton armé » et "du matériau à l'ouvrage " cernent le matériau nouveau, issu de la révolution industrielle. Cyrille Simonnet a raison d'écrire que le béton armé ne cesse d'être inventé dans le second XIXe siècle -262 brevets déposés avant $1906-$, ou plutôt d'être découvert par les savants car les archéologues médiévistes et post-médiévistes nous ont maintes fois montré les traces de tiges métalliques ou de grenaille de fer dans les fondations en béton: le béton armé est, comme la terre armée, un matériau brouillon, plus populaire que savant. François Coignet, « inventeur » du béton aggloméré - et parfois armé - est particulièrement bien mis en valeur, notamment pour ces magnifiques ouvrages que sont l'aqueduc de la Vanne qui donne l'eau potable à Paris et les égouts visitables commandés par son admirateur, Belgrand. La Société centrale des bétons agglomérés créée à Asnières en 1861 produit de l'architecture en pièces détachées, comme certains briquetiers de Toulouse. Cette proto-industrialisation du bâti aurait mérité plus d'attention car elle met en œuvre une décoration, un nouveau paysage dans la périphérie urbaine. Lambot et Lemonnier ne sont pas oubliés même s'ils sont assimilés à des anecdotes (p. 94), ni surtout Hennebique, fondateur du Béton armé dont les photos de chantier assurent l'essentiel des illustrations, ni Cottançin, Polonceau, Eiffel, ni la Société des ingénieurs civils alors à son apogée : le métal issu du trait de plume de l'artiste ingénieur prend racine dans le béton, nouveau terreau de l'industrie; maison, plancher, toit, pont, baignoire, cercueil (p.54). La diffusion du matériau dans les chantiers du bâtiment et des travaux publics durant ces dernières années du XIXe siècle est neuve et constitue le noyau de la thèse originelle: entre le fer, matériau élastique, fibreux, continu, calculable, savant, industriel, coûteux, et le béton, massif, inélastique, inerte, artisanal, incalculable, pas cher, dans un contexte économique restreint et fluctuant, la 
concurrence puis l'association pour étendre la résistance des matériaux et élever les architectures jusqu'aux cieux. Les photographies sont éloquentes: maitrise d'ingénieur, apparition des cols blancs - bureau d'études - et tapisserie métallique de haute lice dans les chantiers. Temps de la diffusion des innovations, de l'enseignement technique, de la formation des cadres intermédiaires, des contremaîtres, choses d'époque. Justement, la composition du matériau, sa granulométrie, son dosage, sa résistance à la traction et à la compression, ses ronds et ses aciers spéciaux, les clinkers, les laitiers, tout cela se transforme et évolue rapidement au cours de cette période.

Le béton est aveugle et insensible à la beauté. Comment lui donner de l'humanité, du sens, du goût? Au début du XXe siècle, ses promoteurs en font le signe de la modernité et Le Corbusier sera, dans l'entre-deux-guerres, son promoteur inconditionnel. Cyrille Simonnet montre bien la figuration du béton armé comme Weltanschauung urbaine de la nouvelle plastique, comme mise en valeur ajoutée, comme signe de prouesse et de performance, de record - le porte-à-faux de Rabut aux Batignolles (1909). Le matériau épouse les formes végétales - on le voit dans les jardins publics imiter le bois - et les verges et les croisées métalliques; il devient fiable parce qu'on peut calculer ses états limites, il résiste à l'incendie, aux bombes... Il devient coque, peau, fil, voile, transparent même avec le verre armé. Il est écrin du sacré - églises - et des arts théâtres.

7 Les deux derniers chapitres portent sur la « tectonique » et la « signalétique » du béton armé et s'appuient sur des études de cas très érudites : par exemple le théâtre des Champs-Élysées construit par Perret (pp.152-154) dont l'analyse permet une comparaison judicieuse avec l'ossature «domino » de Le Corbusier; les architectures nervées et nerveuses du Bauhaus et de Stijl (pp. 165-166) ; les traces du coffrage et des joits, les décors et les revêtements qui embellissent, lissent et étanchent. "L'architecture moderne, ayant banni la décoration, n'a plus d'autres supports pour « raconter» la fonction constructive que son matériau, organisé de façon à signifier cette alternative essentielle: portant, porté »(p.176). Le béton est promu par l'Association française du Beau Béton.

\section{AUTEURS}

\section{ANDRÉ GUILLERME}

CDHTE-Cnam 